\title{
A Negative Binomial Regression Model of the Observed Population Density of Heterodera glycines after Annual Corn Rotation in Nebraska
}

\author{
Oscar Pérez-Hernández, ${ }^{1, \dagger}$ Loren J. Giesler, ${ }^{2}$ and Joseph M. Hilbe ${ }^{3}$ \\ ${ }^{1}$ School of Agricultural Sciences, Northwest Missouri State University, Maryville, MO 64468 \\ ${ }^{2}$ Department of Plant Pathology, University of Nebraska-Lincoln, Lincoln, NE 68583 \\ ${ }^{3}$ T. Denny Sanford School of Social and Family Dynamics, Arizona State University, Tempe, AR 85287 (deceased in 2017)
}

\begin{abstract}
In Nebraska, rotation of soybean (Glycine max) fields to corn (Zea mays) is a major practice to manage the soybean cyst nematode (SCN; Heterodera glycines). However, factors associated with SCN population density decline during corn rotation are not clearly defined. This study addresses that question using a modeling approach. Seventy-nine fields were sampled in 2009, 2010, and 2011 to determine SCN population densities (eggs $/ 100 \mathrm{~cm}^{3}$ of soil) before and after rotation. After rigorous field screening and model testing and validation, the regression model $\widehat{\log (P f})=-2.3360+0.8368 \log P i+0.4333 p H$ was developed, where $\log \mathrm{P} f$ is the natural log of SCN eggs at the end of the rotation year, $\mathrm{P} i$ is the population density before rotation, and $\mathrm{pH}$ is the soil $\mathrm{pH}$. Model goodness-of-fit was assessed through residual analysis, information criteria, and other remedial measures. Model overdispersion was 1.04. Validation in a 50 and a $75 \%$ random sample from the original data set showed

little change in model regression coefficients, standard errors, and associated significance, confirming model fit and performance. The model indicates that for one-unit increase in soil $\mathrm{pH}$, SCN $\mathrm{P} f$ is expected to increase by $53.7 \%$ at constant $\mathrm{P} i$, and correspondingly, a $10 \%$ change in $\mathrm{P} i$ will result in about $8.3 \%$ change in $\mathrm{P} f$ at constant soil $\mathrm{pH}$. The model suggested that SCN population levels before corn rotation and soil $\mathrm{pH}$ are major determinants of observed SCN population density reduction after annual corn rotation in Nebraska. This model has potential for use in SCN risk analysis and in predicting SCN population decline after corn rotation in the state.

Keywords: cyst nematode epidemiology, negative binomial, corn rotation, nematode management, oilseeds and legumes, disease management, epidemiology, disease development and spread
\end{abstract}

Since its discovery in North Carolina in 1954 (Winstead et al. 1955), the soybean cyst nematode (SCN; Heterodera glycines Ichinohe, 1952) has been considered the most economically important pathogen of soybean (Glycine max L.) in the United States (Doupnik 1993; Ross 1962; Wrather and Koenning 2006). Soybean yield suppression due to SCN was estimated at 35 million metric tons during 2006 (Wrather 2008), a much higher yield reduction than that caused by any other soybean disease in the country (Wrather and Koenning 2006). In Nebraska (the seventh largest soybean producing state in the United States; NASS 2018), yield losses due to SCN were estimated at $\$ 40$ million in 2012 (Wilson and Giesler 2013).

$\mathrm{SCN}$ is a microscopic, cyst-forming, obligate plant parasitic animal that infects soybean and other cultivated and noncultivated plants (Johnson et al. 2008; Riggs 1992). In susceptible hosts, juvenile nematodes enter the root, migrate toward the central cylinder, and establish a permanent feeding site near the vascular tissue, where they complete adulthood and reproduction after three molts (Lauritis et al. 1983; Niblack 2005). Conversely, in nonhost crops like corn, wheat, and oats, juveniles are unable to establish a permanent feeding site and reproduce, and eventually die (Chen et al. 2008). Both juveniles and other SCN developmental stages remaining in the soil are affected by soil factors, weather conditions, and management practices imposed during the nonhost rotation cycle and the off-season (Noel 2008).

In Nebraska, management of SCN relies almost entirely on rotation of soybean fields to corn (Zea mays L.) and use of

${ }^{\dagger}$ Corresponding author: O. Pérez-Hernández; ohernandez@nwmissouri.edu

Funding: Funding for this work was provided by the Nebraska Soybean Board Grant No. 55506.

The author(s) declare no conflict of interest.

Accepted for publication 18 June 2019.

(C) 2019 The American Phytopathological Society
SCN-resistant soybean varieties (Giesler and Wilson 2011). Percent decline of SCN population densities in annually rotated corn fields in the state was recently estimated to vary between 10 and $90 \%$ (PérezHernández and Giesler 2014). While it is well established that SCN population densities can be reduced significantly during the corn rotation cycle (Koenning et al. 1993; Noel 2008; Pérez-Hernández and Giesler 2014; Porter et al. 2001; Young and Hartwig 1992), the factors associated with such a decline in field conditions are not clearly defined. Soil temperature, tillage, soil texture, and $\mathrm{pH}$ have been associated to SCN abundance (Alston and Schmitt 1988; Pedersen et al. 2010; Ross 1964; Slack et al. 1972; Westphal et al. 2009; Workneh et al. 1999), but the inferred association has been derived from studies focused on the soybean growing season. Little is known about the relationships of those factors with the observed SCN mortality during the annual corn rotation cycle, which includes the growing season and an off-season or overwintering period. Identification of major factors associated with SCN population density reduction in corn can provide the basis for SCN risk assessment, which ultimately can be useful for better management decisions. Regression models offer a robust approach to identify and understand factors and interactions, with the advantage of elucidating quantitative variable relationships that are often difficult to identify with ordinary class variable models (Jones and Perry 1978; Kutner et al. 2004; Paul and Munkvold 2005). The objective of this research was to identify, using a modeling approach, major factors associated with the observed SCN population density reduction after annual corn rotation in Nebraska.

\section{Materials and Methods}

SCN data collection. Data of SCN population densities from 79 fields were initially used for the analysis. Field selection, sampling methodology, and determination of SCN population densities in each field are described in detail elsewhere (Pérez-Hernández and Giesler 2014). In essence, from Nebraska SCN surveys, commercial production fields ( 37 to 55 ha in size) with a history of SCN and in soybeancorn rotation were selected in 2009, 2010, and 2011 in the major soybean growing areas of the state. In each field, ten $3 \times 3 \mathrm{~m}$ sampling 
grids were selected systematically in a zig-zag pattern, and the center of each grid was referenced for site-specific resampling using a handheld global positioning system device (GeoExplorer 2008 series Trimble, Westminster, CO). From each grid, twenty 2.5 -cm-diameter, 15- to 20-cm-deep soil cores were collected every $60 \mathrm{~cm}$ and mixed to a composite sample. The SCN population density $\left(\mathrm{eggs} / 100 \mathrm{~cm}^{3}\right.$ of soil) in each grid was determined from a $100 \mathrm{~cm}^{3}$ subsample using standard sieving techniques for SCN (Khan 2008). Next, an average population density from the 10 grids was determined for each field. Each field was sampled twice: in midspring, before corn planting, and in midspring of the following year, preceding soybean planting. The SCN population density determined in the first spring sampling is herein referred to as $\mathrm{SCN}$ initial population density $(\mathrm{P} i)$ or population density before rotation, and the population density estimated in the second spring, after annual rotation, is referred to as $\mathrm{SCN}$ final population density $(\mathrm{P} f)$.

Model construction. Construction of the model was carried out in four major steps: (i) selection of input variables, (ii) preliminary diagnostics and fit of the first model, (iii) model refinement and selection, and (iv) model validation. Each of these steps is described next.

Model input variables. The response variable was the SCN P $f$ in each field, expressed as the number of $\mathrm{SCN}$ eggs $/ 100 \mathrm{~cm}^{3}$ of soil. The explanatory variables were selected based on published research on relationship of environmental factors with $\mathrm{SCN}$. In addition, other variables that were considered to affect $\mathrm{SCN}$ during the rotation year were also included. The set of variables comprised: (i) $\mathrm{SCN} \mathrm{Pi}$, (ii) soil $\mathrm{pH}$, (iii) soil organic matter (OM; \%), (iv) a soil texture index (TI), (v) accumulated rainfall in the corn growing season (AR; mm), (vi) number of days with soil temperature below freezing in the off-season $\left(\mathrm{ST} ;{ }^{\circ} \mathrm{C}\right)$, (vii) tillage as a binary indicator variable ( $=0$ if no-till, 1 otherwise), and (viii) irrigation (= 0 if nonirrigated, 1 otherwise). Soil pH, OM, and TI for each field were determined from a composite sample representing each field and analyzed by a commercial soil testing laboratory (Wards Laboratories, Inc., Kearney, NE). The TI was derived from a principal component analysis of the sand, silt, and clay proportions in the composite soil sample (Pérez-Hernández and Giesler 2014). In such analysis, sand, silt, and clay showed high collinearity and were reduced to the first principal component, which explained 93\% of the total variability in the data set. The score of that principal component represented the TI in each field.

The variables AR and ST were obtained for each field from the Nebraska Rainfall Assessment and Information Network (NeRAIN 2013), weather stations of the National Weather Service (NWS, 2013), and automated weather stations of the High Plains Regional Climate Center (HPRCC 2013). The AR was estimated for the corn growing season (1 May to 30 October), whereas ST was estimated for the off-season (1 November to 30 April). AR for each field was estimated by inverse distance weighting (IDW) interpolation using daily precipitation data from weather stations located within a $25-\mathrm{km}$ radius from each target field. The distance from the weather station of interest to each target field was calculated from the latitude and longitude of both the station and the target field using the Haversine formula (Sinnott 1984) in a routine written in Python programming language (Python 3.1.5., Python Software Foundation, Delaware, U.S.A.). The procedure for the IDW is given by:

$$
\hat{x}=\sum_{1}^{n} x_{i} w_{i} / \sum_{i=1}^{n} w_{i}
$$

$w$ here: $\hat{x}$ is the IDW estimate, $x_{i}$ is the particular measurement at the $i$ th surrounding station, and the weight function $w_{i}$ is derived from the inverse of the distance between the target field and the $i$ th surrounding station (Hubbard and You 2005). Data of ST, also estimated by IDW spatial interpolation, were estimated from daily average soil temperature of the closest automated weather station to a target field. Available automated stations were within a maximum radius of $35 \mathrm{~km}$ of the target fields, and the corresponding distance from a station to a target field was calculated as described above. Information on tillage and irrigation was obtained from direct assessments of the field during the sampling, and from agronomic questionnaires sent to the cooperating growers.
Preliminary diagnostics and fit of first model. Preliminary diagnostics for the response and explanatory variables was done by examination of the marginal distribution of the response variable $(\mathrm{P} f)$, description of $\mathrm{P} f$ mean and variance relationship, and summary statistics for the predictors. The quantitative explanatory variables were first evaluated for their association with $\mathrm{P} f$ using correlation analysis (PROC CORR of SAS, SAS Institute Inc., Cary, NC). Given that the response variable is a count, the standard Poisson model was fitted first. This Poisson regression model was not pursued because true, severe overdispersion was confirmed in the data (Hilbe 2011; Stroup 2013). Further, since neither too many nor no zeroes existed in the data set for consideration of other Poisson model variations, a negative binomial model with traditional parameterization (NB2; Hilbe 2011) was implemented (PROC GENMODE of SAS; lm-nbg function of R). The NB2 model with mean $\mu$ and variance function $\mu+$ $\alpha \mu^{2}$ has density:

$$
f\left(y_{i} \mid \mu, \alpha\right)=\frac{\Gamma\left(y+\alpha^{-1}\right)}{\Gamma(y+1) \Gamma\left(\alpha^{-1}\right)}\left(\frac{\alpha^{-1}}{\alpha^{-1}+\mu}\right)^{\alpha^{-1}}\left(\frac{\mu}{\alpha^{-1}+\mu}\right)^{y}
$$

where: $\alpha \geq 0, y=0,1,2, \ldots$, and $\Gamma$ (.) is the gamma function (Cameron and Trivedi 2013).

Due to the relatively small data set and number of selected explanatory variables, fitting of a full second-order model was not considered and neither was the use of an automated algorithm for selection of a candidate model. Instead, a full first-order model was fitted to the data ( $\mathrm{P} i$ natural log-transformed for consistency with the negative binomial model link function), and the variables that showed significance $(P$ value $)$ of at least 0.50 were retained. To further ensure that important variables were not left out, the model was fitted to one variable at a time, and only variables with a significance $\leq 0.50$ were also retained. With the retained variables up to this stage, as a final step in the selection of a candidate model, a full first-order model was fitted and the proper functional form of the predictor variables was assessed using partial regression plots (avPlots function in the car package of R: R Foundation for Statistical Computing, Vienna, Austria). Partial regression plots are scatterplots of residuals, where the residuals in the $y$-axis are obtained from regressing the response on all the regressors, but a regressor $x_{i}$. Therefore, these residuals are the part of the response variable that is not explained by all the regressors except $x_{i}$ (Fox and Weisberg 2011). Correspondingly, the residuals in the $\mathrm{x}$-axis are obtained by regressing $x_{i}$ on the other regressors. These residuals represent the part of $x_{i}$ that is not explained by the other regressors or that remains when the other regressors are conditioned (Fox and Weisberg 2011). Following assessment of the partial regression plots, a candidate model was constructed with the explanatory variables that showed a significant relationship (linear or quadratic) with or explanatory power to the response.

Model refinement and selection. The goodness-of-fit and refinement of the candidate model selected up to this point was done through residual analysis, determination of influential observations, and goodness-of-fit tests. Residual analysis included Pearson and Deviance residuals, with generated $95 \%$ confidence intervals as graphical envelopes for the latter according to the procedure proposed by Svetliza and Paula (Svetliza and Paula 2003). Presence of influential observations was determined through difference in fitted values (DFFITS), Cook's Distance, and DFBETAS methods, implemented in the R software. Also, the leverage of identified unusual observations was assessed using the hat-values as a leverage measure (influenceIndexPlot function of the car package of R) (Fox and Weisberg 2011). Goodness-of-fit tests included deviance, likelihood ratio tests (Hilbe 2011), as well as the Akaike's (AIC) and Bayesian information (BIC) criteria (PROC GENMOD of SAS). In addition, special attention was paid to the value of the dispersion statistics or Pearson $\chi^{2}$ for assessment of the equidispersion in the model. After the refinement process was completed, goodness-of-fit tests were performed again on the model. The model developed at this stage was the final model and was fitted using robust estimation of standard errors (Hilbe 2014). 
Model validation. The final model was validated in two random samples containing 50 and $75 \%$ of the observations from the original data set ( 25 and 35 data points, respectively). The random samples were taken from the data set using the SURVEYSELECT procedure of SAS. Model performance was validated through the relative change in the regression coefficients of each of the predictors and their associated standard errors and significance level. Predictions of single observations from the data set were also made to verify model performance. In addition, predicted versus observed $\mathrm{P} f$ values for the random samples was assessed with simple linear regression.

\section{Results}

Distribution of the response, summary statistics, and correlations. The response variable (SCN Pf) showed a skewed distribution (Fig. 1) and extremely different values for the unconditional mean and variance, which had a nonlinear relationship, thus suggesting overdispersion. The suggested overdispersion was confirmed by the high value of the Pearson $\chi^{2} / \mathrm{df}$ or dispersion statistics $(=18.5)$ of the Poisson regression model that was fitted to the data before the construction of the negative binomial regression model. The mean and variance of $\mathrm{P} f$ varied for each level of tillage, suggesting this variable as a good $\mathrm{P} f$ predictor candidate. Significant positive correlations $(P \leq 0.05)$ were observed between the response variable $(\mathrm{P} f)$ and $\mathrm{P} i, \mathrm{pH}$, and $\mathrm{ST}$ (Table 1). Positive correlations

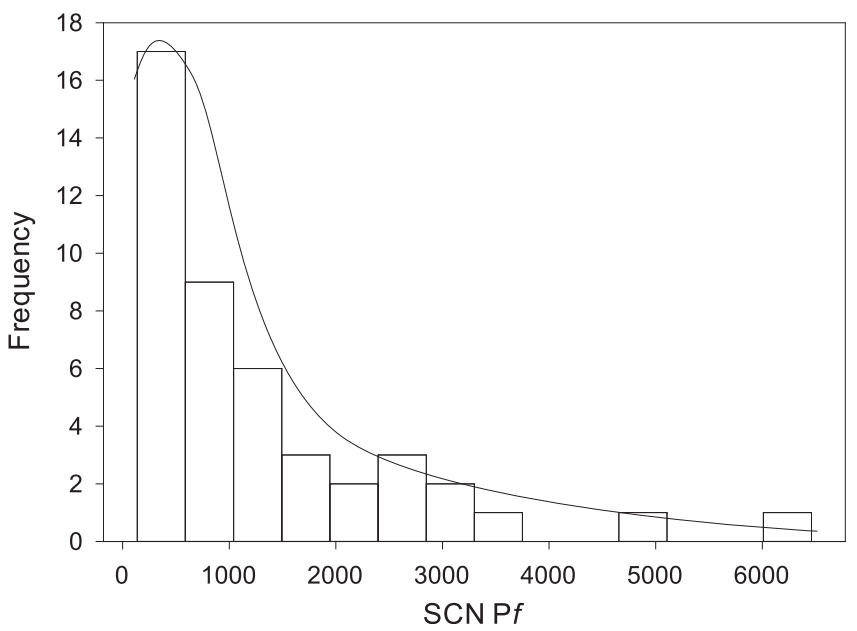

Fig. 1. Frequency distribution of the $S C N$ population density (eggs/100 $\mathrm{cm}^{3}$ of soil) observed after annual corn rotation $(\mathrm{P} f)$ in the selected fields in Nebraska.

Table 1. Pearson correlation coefficients between the response variable ( $\mathrm{P} f)$ and the quantitative explanatory variables used in model development

\begin{tabular}{lccccccc}
\hline Variable & $\mathbf{P} \boldsymbol{f}$ & $\mathbf{P i}$ & $\mathbf{p H}$ & $\mathbf{O M}$ & $\mathbf{T I}$ & $\mathbf{A R}$ & $\mathbf{S T}$ \\
\hline $\mathrm{Pf}^{\mathrm{s}}$ & 1.00 & $0.84 \mathrm{a}^{\mathrm{t}}$ & $0.27 \mathrm{~b}^{\mathrm{t}}$ & $-0.03 \mathrm{c}^{\mathrm{t}}$ & $-0.12 \mathrm{c}$ & $-0.10 \mathrm{c}$ & $0.29 \mathrm{a}$ \\
$\mathrm{Pi}^{\mathrm{u}}$ & & 1.00 & $0.05 \mathrm{c}$ & $-0.18 \mathrm{c}$ & $-0.26 \mathrm{~b}$ & $-0.07 \mathrm{c}$ & $0.29 \mathrm{a}$ \\
$\mathrm{pH}^{\mathrm{v}}$ & & & 1.00 & $0.42 \mathrm{a}$ & $0.41 \mathrm{a}$ & $-0.11 \mathrm{c}$ & $-0.05 \mathrm{c}$ \\
$\mathrm{OM}^{\mathrm{w}}$ & & & & 1.00 & $0.95 \mathrm{a}$ & $0.01 \mathrm{c}$ & $-0.25 \mathrm{c}$ \\
$\mathrm{TI}^{\mathrm{x}}$ & & & & & 1.00 & $-0.11 \mathrm{c}$ & $-0.22 \mathrm{c}$ \\
$\mathrm{AR}^{\mathrm{y}}$ & & & & & & 1.00 & $0.17 \mathrm{c}$ \\
$\mathrm{ST}^{\mathrm{z}}$ & & & & & & & 1.00 \\
\hline
\end{tabular}

s SCN final population density (eggs $/ 100 \mathrm{~cm}^{3}$ of soil) or population density after annual corn rotation.

t a, Significant $(P \leq 0.05)$. b, Marginally significant $(P$ between 0.06 and $0.10)$. c, Not significant $(P>0.10)$.

u SCN initial population density (eggs $/ 100 \mathrm{~cm}^{3}$ of soil) or population density before corn rotation.

v Soil pH.

w Soil organic matter.

x Soil texture index obtained from principal component analysis of sand, silt, and clay.

y Accumulated rainfall in $\mathrm{mm}$ in the corn growing season (1 May to 30 October).

$\mathrm{z}$ Number of days with soil temperature below freezing in the off-season (1 November to 30 April). were also observed between $\mathrm{pH}$ and $\mathrm{OM}$ and $\mathrm{pH}$ and TI. The variable $\mathrm{P} i$ was positively correlated with ST and negatively correlated with TI.

Negative binomial regression model. The full first-order negative binomial regression model fitted to the eight variables indicated significant predictor capability for $\mathrm{P} i, \mathrm{pH}$, and tillage (Table 2). TI showed marginal significance $(P=0.09)$ and OM, AR, ST, and irrigation were not significant at the 0.05 level. Fitting of each variable at a time showed significance only for $\mathrm{SCN} \mathrm{P} i$, soil $\mathrm{pH}$, and ST (Table 3). The partial regression plots with six retained variables suggested that $\mathrm{P} i$ had a linear relationship with $\mathrm{P} f$ given the rest of the variables were in the model (Fig. 2A). Variable $\mathrm{pH}$ was also linearly related to $\mathrm{P} f$ given that the other variables were present in the model (Fig. 2B). Tillage and TI showed a weak linear relationship with Pf, but neither a quadratic nor a cubic functional form was suggested by the partial regression scatter plot (Fig. 2C and D). Plots for irrigation and ST showed a random scattering of points suggesting no relationship with the response variable $\mathrm{P} f$ given the other variables were in the model (Fig. 2E and F). In all the partial regression plots,

Table 2. Estimates of the regression coefficients, associated standard errors, and significance of the fixed effects (intercept and explanatory variables) from fitting of the full first-order negative binomial regression model

\begin{tabular}{|c|c|c|c|c|c|}
\hline Effect & Estimate & Std error & $\begin{array}{l}\text { 95\% Confidence } \\
\text { limits }\end{array}$ & $Z$ value & $P>\mathbf{Z}$ \\
\hline Intercept & -2.2029 & 1.0124 & $-4.1872-0.2186$ & -2.18 & 0.0296 \\
\hline $\log i^{t}$ & 0.8158 & 0.0579 & 0.70240 .9292 & 14.10 & $<0.0001$ \\
\hline $\mathrm{pH}^{\mathrm{u}}$ & 0.4131 & 0.0683 & 0.27930 .5469 & 6.05 & 0.0001 \\
\hline $\mathrm{OM}^{\mathrm{v}}$ & -0.0421 & 0.1468 & -0.32980 .2456 & -0.29 & 0.7744 \\
\hline $\mathrm{TI}^{\mathrm{w}}$ & -0.0828 & 0.1132 & -0.30470 .1392 & -0.73 & 0.4649 \\
\hline $\mathrm{AR}^{\mathrm{x}}$ & 0.0003 & 0.0009 & -0.00150 .0021 & 0.30 & 0.7606 \\
\hline $\mathrm{ST}^{\mathrm{y}}$ & 0.0013 & 0.0018 & -0.00310 .0038 & 0.19 & 0.8475 \\
\hline Tillage $^{\mathrm{z}}$ & 0.4266 & 0.1782 & 0.07730 .7758 & 2.39 & 0.0167 \\
\hline Irrigation $^{z}$ & -0.2013 & 0.2062 & -0.60540 .2029 & -0.98 & 0.3291 \\
\hline $\begin{array}{ll}\text { SCN ini } \\
\text { transform } \\
\text { u Soil pH. } \\
\text { v Soil orga } \\
\text { w Soil text } \\
\text { and clay. } \\
\text { x Accumul } \\
\text { October) } \\
\text { y Number } \\
\text { Novemb } \\
\text { z Entered i }\end{array}$ & $\begin{array}{l}\text { tial popula } \\
\text { ed). } \\
\text { nic matter. } \\
\text { Ire index ob } \\
\text { ated rainfal } \\
\text { of days with } \\
\text { r to } 30 \mathrm{Apr} \\
\mathrm{n} \text { the model }\end{array}$ & $\begin{array}{l}\text { tion densit } \\
\text { tained from } \\
1 \text { in } \mathrm{mm} \text { in } \\
\text { soil tempe } \\
\text { il). } \\
\text { as binary }\end{array}$ & $\begin{array}{l}\text { ncipal componen } \\
\text { e corn growing } \\
\text { ures below freezin } \\
\text { ables. }\end{array}$ & $\begin{array}{l}\text { alysis of } \\
\text { on (1 } \\
\text { the off }\end{array}$ & $\begin{array}{l}\text { and, silt, } \\
\text { y to } 30 \\
\text { eason (1 }\end{array}$ \\
\hline
\end{tabular}

Table 3. Estimates of the regression coefficients and their associated standard errors and significance after fitting the negative binomial model with one variable at a time

\begin{tabular}{|c|c|c|c|c|c|}
\hline Effect & Estimate & Std error & $\begin{array}{l}\text { 95\% Confidence } \\
\text { limits }\end{array}$ & $Z$ value & $P$ \\
\hline $\mathrm{gP}^{\mathrm{t}}$ & 0.8347 & 0.0592 & 0.71870 .9508 & 14.10 & $<0.00$ \\
\hline $\mathrm{H}^{\mathrm{u}}$ & 0.5043 & 0.1522 & 0.20610 .8026 & 3.31 & 0.000 \\
\hline $\mathrm{OM}^{\mathrm{v}}$ & -0.0198 & 0.1603 & -0.33410 .2944 & -0.12 & .90 \\
\hline $\mathrm{I}^{\mathrm{w}}$ & -0.0590 & 0.10 & -0.2553 & -0.59 & 0.55 \\
\hline $\mathrm{AR}^{\mathrm{x}}$ & 0.0003 & 0.0009 & -0.00150 .0021 & 0.30 & 0.76 \\
\hline $\mathrm{ST}^{\mathrm{y}}$ & 0.0105 & 0.0042 & 0.00230 .0187 & 2.50 & 0.01 \\
\hline Tillage $^{z}$ & 0.2221 & 0.2863 & -0.33920 .7833 & 0.78 & 0.43 \\
\hline Irrigation $^{z}$ & -0.6135 & 0.3464 & -1.29240 .0653 & -1.77 & 0.076 \\
\hline
\end{tabular}

${ }^{t}$ SCN initial population density (eggs $100 / \mathrm{cm}^{3}$ of soil, natural logtransformed)

u Soil $\mathrm{pH}$.

v Soil organic matter.

w Soil texture index obtained from principal component analysis of sand, silt, and clay.

x Accumulated rainfall in $\mathrm{mm}$ in the corn growing season (1 May to 30 October).

y Number of days with soil temperatures below freezing in the off-season (1 November to 30 April).

${ }^{\mathrm{z}}$ Entered in the model as binary variables. 
observations 32 and 37 stood out as potential outliers. This issue was dealt with more carefully in the model refinement step.

Based on all the aforementioned assessments, a candidate model with the variables $\mathrm{P} i, \mathrm{pH}$, tillage, and TI was selected (Table 4). The model is written as:

$$
\widehat{\log (P f})=-\hat{\beta}_{0}+\hat{\beta}_{1} \log P i+\hat{\beta}_{2} p H+\hat{\beta}_{3} \text { Tillage }-\hat{\beta}_{4} T I .
$$

The Pearson $\chi^{2} / \mathrm{df}$ corresponding to the dispersion statistics for this model was 1.02 .

Model refinement and selection. Residual plots. Pearson and deviance residual plots showed no systematic features or patterns, indicating overall a good fit of the candidate model (Figs. 3 and 4). Only the residuals for texture index show a slight pattern for low and high values. The $95 \%$ confidence interval for the deviance residuals comprised all observations, except a couple of observations that appeared slightly out of the interval boundaries (Fig. 4). The lack-of-fit test computed for the numerical predictors in this model indicated no lack-of-fit ( $t$ values of $0.036,0.025$, and 0.013 for $\mathrm{P} i, \mathrm{pH}$, and TI, respectively, with associated $P$ values of $0.85,0.87$, and 0.91 ). However, the Pearson residual value of observations 32 and 37 consistently appeared isolated from the rest of the cloud, suggesting these observations could be extreme and, likely, influential in the model fit (Fig. 3A-D). These observations also stood out as extreme in the partial regression plots (Fig. 2A-F).

Influential observations. The difference in fitted values (DFFITS) method suggested observation 32 as influential on single fitted values according to the DFFITS guidelines for influential observations for small to medium sized data sets (Fig. 5). Cook's Distance (D) method identified observations 22, 32, and 37 as having the greatest Cook's Distance (Fig. 6), yet none of these observations were influential on all predicted values based on the Cooks' Distance guidelines for influential observations: if $\mathrm{D}>F(0.50, p, n-p)$, where $p$ is the number of predictors and $n$ is the number of observations in the data set, then observation is influential. Value of D for observations 22, 32, and 37 was $0.1208,0.1251$, and 0.1252 , respectively. The DFBETAS method, which measures the influence of the $i$ th observation on each estimated regression coefficient, identified observation 32 as influential only on the regression coefficient for texture index (Fig. 7).

Follow up assessment of observations 32 and 37 confirmed they had a high leverage in the estimators of the regression coefficients and their associated significance level in the candidate model (Table 5; Fig. 6). In other words, the coefficient estimates and their corresponding $P$-values in the candidate model changed significantly with and without these observations (Table 5). In particular, the sign of the regression coefficient for tillage changed from positive to negative, and the regression coefficient for TI changed by 55\% (Table 5) when the model was fitted to the data set without observations 32 and

Table 4. Model information criteria and deviance of the starting full first order model and the selected candidate negative binomial regression model

\begin{tabular}{|c|c|c|c|}
\hline \multirow[b]{2}{*}{ Model } & \multicolumn{3}{|c|}{ Information criteria } \\
\hline & $\mathrm{AIC}^{\mathrm{v}}$ & BICw $^{\mathbf{w}}$ & DVC $^{x}$ \\
\hline Starting model ${ }^{\mathrm{y}}$ & 671.97 & 682.81 & 2.22 \\
\hline Candidate selected model $\mathrm{z}$ & 527.64 & 541.64 & 1.32 \\
\hline
\end{tabular}

$v$ Akaike's information criterion

${ }^{w}$ Bayesian information criterion.

$x$ Deviance.

y Full first-order negative binomial regression model with the predictors SCN initial population density ( $\mathrm{P} i$, natural log-transformed), soil $\mathrm{pH}$, texture index (TI), tillage and irrigation.

z Negative binomial regression model: $\log (P f)=-\hat{\beta}_{0}+\hat{\beta}_{1} \log P i+\hat{\beta}_{2} p H+$ $\hat{\beta}_{3}$ Tillage $-\hat{\beta}_{4} T I$ selected after fitting the full first order model and application of remedial measures.
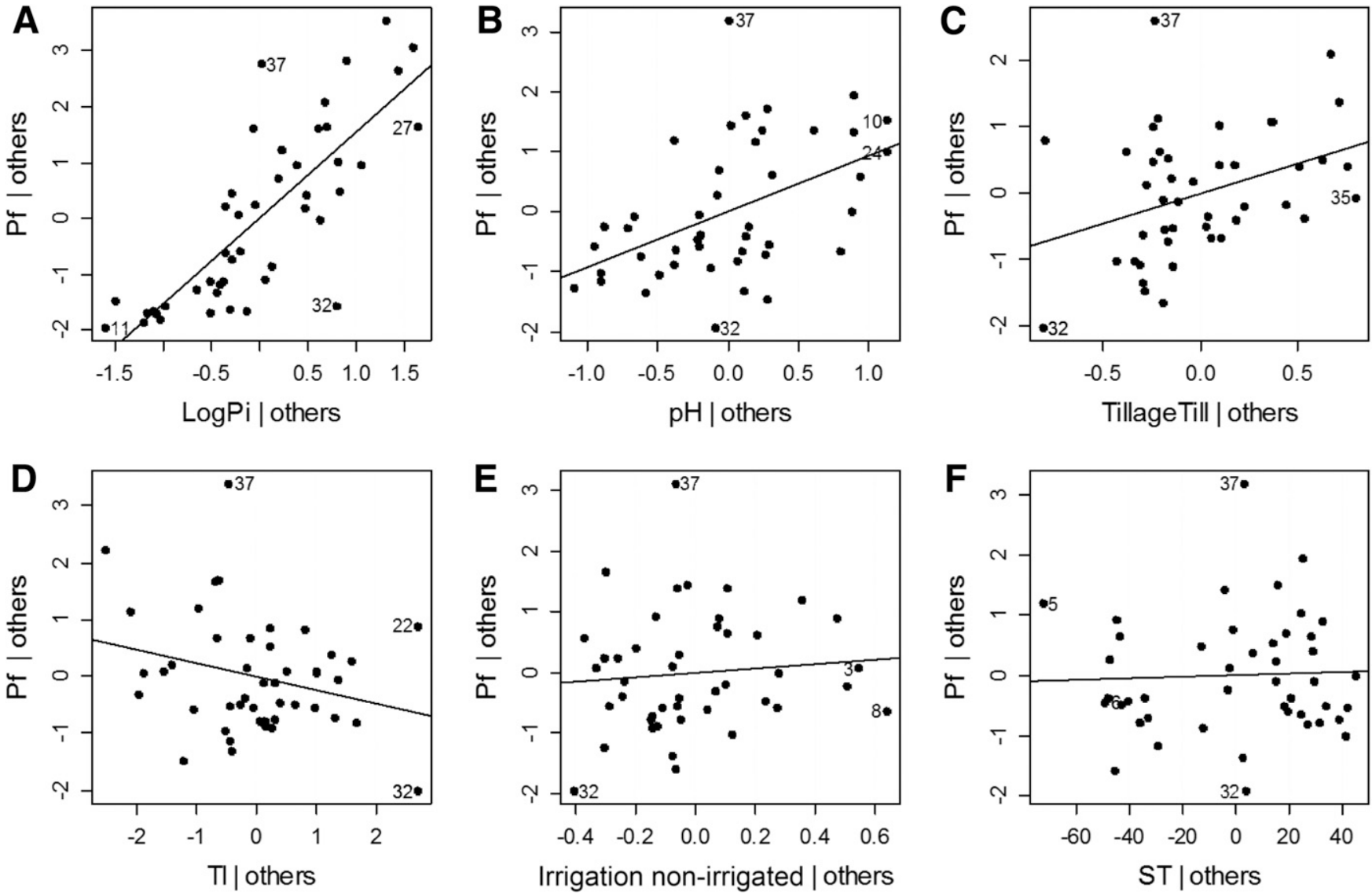

Fig. 2. Partial regression plots of the SCN population density after annual corn rotation (Pf) on $\mathbf{A}, \mathrm{SCN}$ initial population density (natural log-transformed, LogPi), B, Soil pH, C, Tillage, D, Texture index (TI), E, Irrigation, and F, Number of days with soil temperature below freezing (ST). Regression model was a negative binomial. 
37 (Table 5). This confirmed that those observations were influential in the model fit. Regression coefficients for $\mathrm{P} i$ and soil $\mathrm{pH}$, in their turn, underwent little change.

Based on all the above remedial measures and model refinement, the final selected model is the one having SCN initial population density and soil $\mathrm{pH}$ as predictors:

$$
\widehat{\log (P f} f)=-\hat{\beta}_{0}+\hat{\beta}_{1} \log P i+\hat{\beta}_{2} p H .
$$
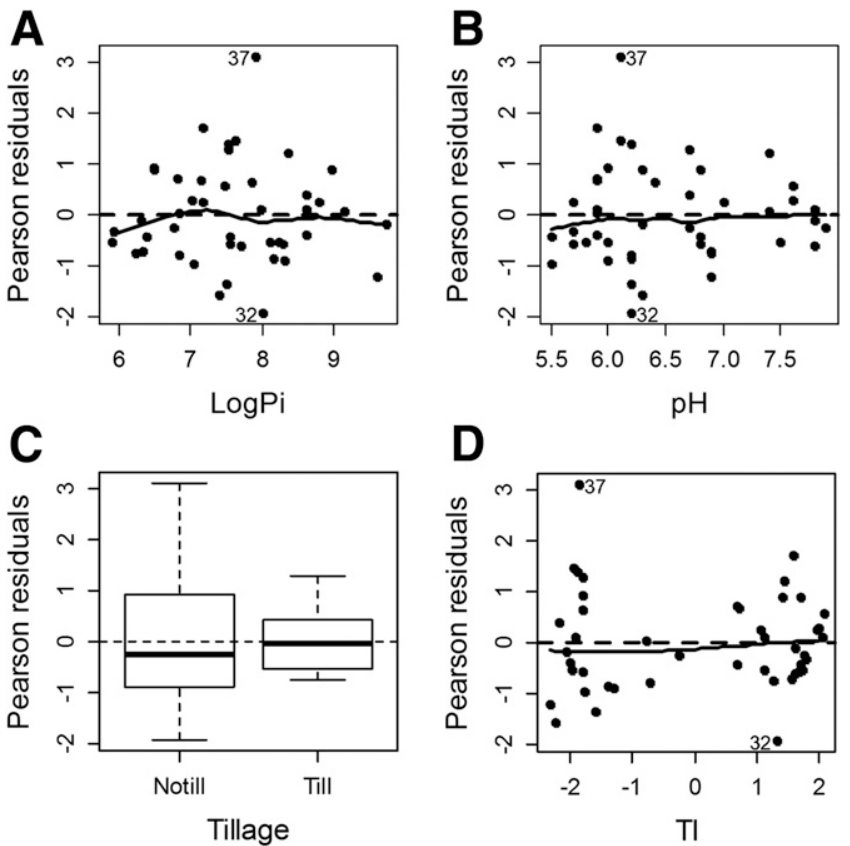

Fig. 3. Pearson residual plots for the candidate negative binomial regression model: $\log (P f)=-\hat{\beta}_{0}+\hat{\beta}_{1} \log P i+\hat{\beta}_{2} p H+\hat{\beta}_{3}$ Tillage $-\hat{\beta}_{4} T$ T. A, SCN initial population density (natural log-transformed, LogPi), B, Soil pH, C, Tillage, and D, Texture index (TI).

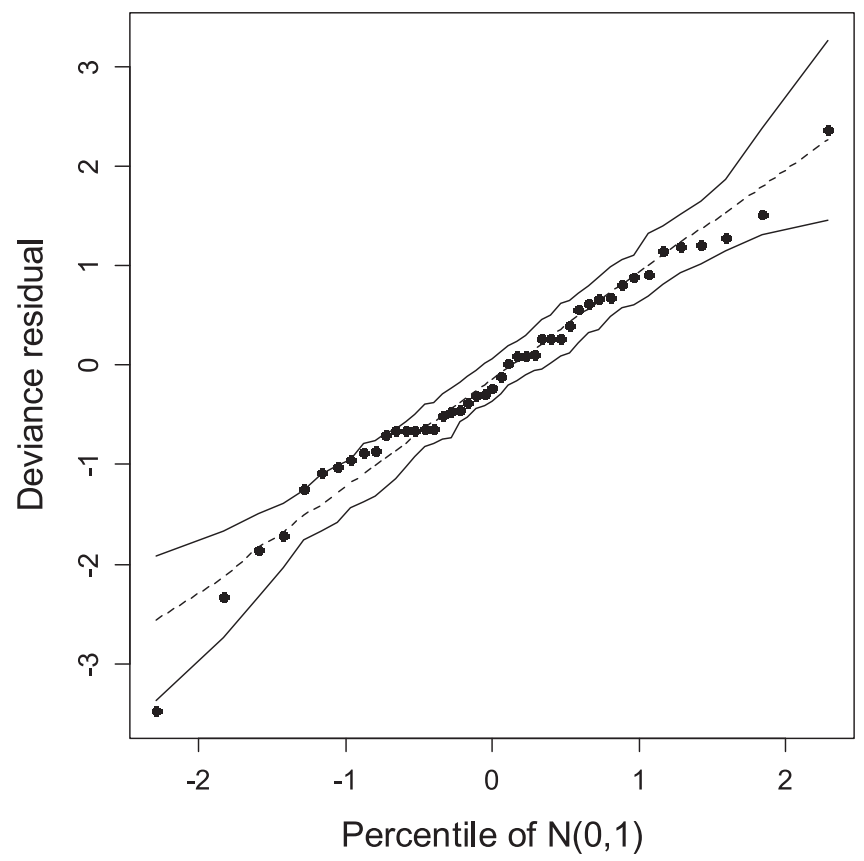

Fig. 4. Plot of deviance residuals (with generated $95 \%$ confidence envelopes) against the percentile of a normal distribution for the candidate negative binomial regression model: $\log (P f)=-\hat{\beta}_{0}+\hat{\beta}_{1} \log P i+\hat{\beta}_{2} p H+\hat{\beta}_{3}$ Tillage $-\hat{\beta}_{4} T I$. where $\log P i$ is the $\mathrm{SCN}$ initial population density (natural log-transformed), $\mathrm{pH}$ is the soil $\mathrm{pH}$, and $\mathrm{Tl}$ is the soil texture index.
With the actual values of the regression coefficients, the model is written as:

$$
\widehat{\log (P f})=-2.3360+0.8368 \log P i+0.4333 p H,
$$

or equivalently: $\mathrm{P} f=\exp ^{\{-2.3360+0.8368(\log \mathrm{P} i)+0.4333 \mathrm{pH}\}}$. The Pearson $\chi^{2}$ statistics for this model was 1.04 .

Goodness-of-fit tests. The goodness-of-fit tests (log-likelihood ratio and deviance) indicated good fit of the model: Log-likelihood ratio was $61.87(P<0.0001)$, and the $\chi^{2}$ test for the deviance was 34.89 $(P=0.2878)$. The Akaike's and Bayesian information criteria of the

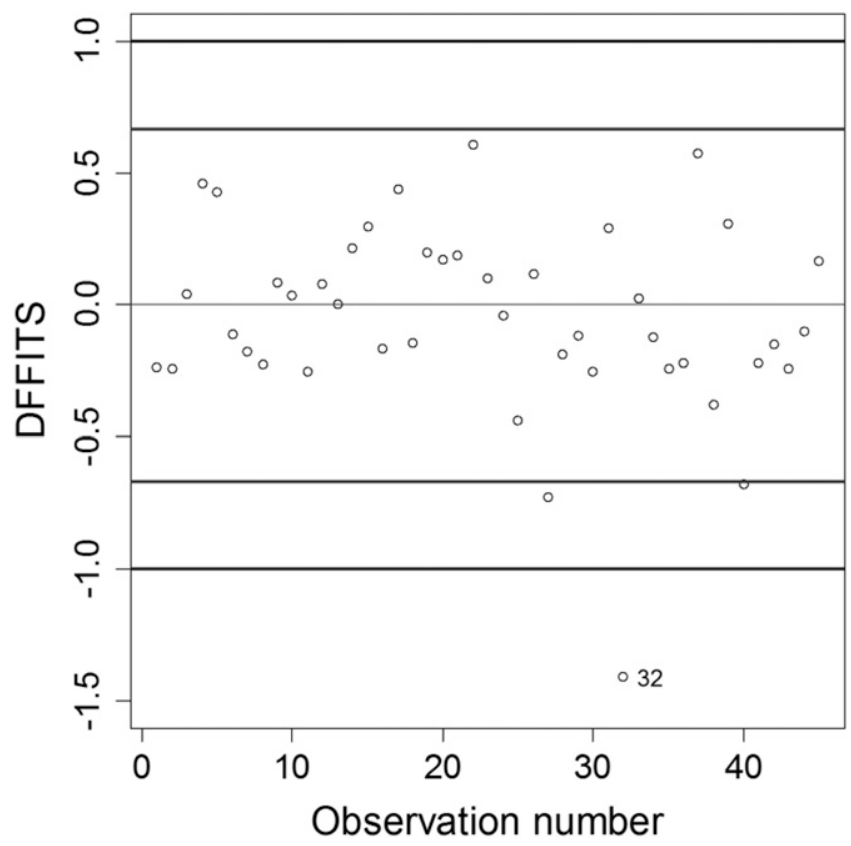

Fig. 5. Difference in fitted values (DFFITS) of the observations after fit of the candidate negative binomial regression model: $\log (P f)=-\hat{\beta}_{0}+\hat{\beta}_{1} \log P i+\hat{\beta}_{2} p H+$ $\hat{\beta}_{3}$ Tillage $-\hat{\beta}_{4} \mathrm{Tl}$. Influential observations on single fitted values are shown outside the border lines with absolute value $>1$.

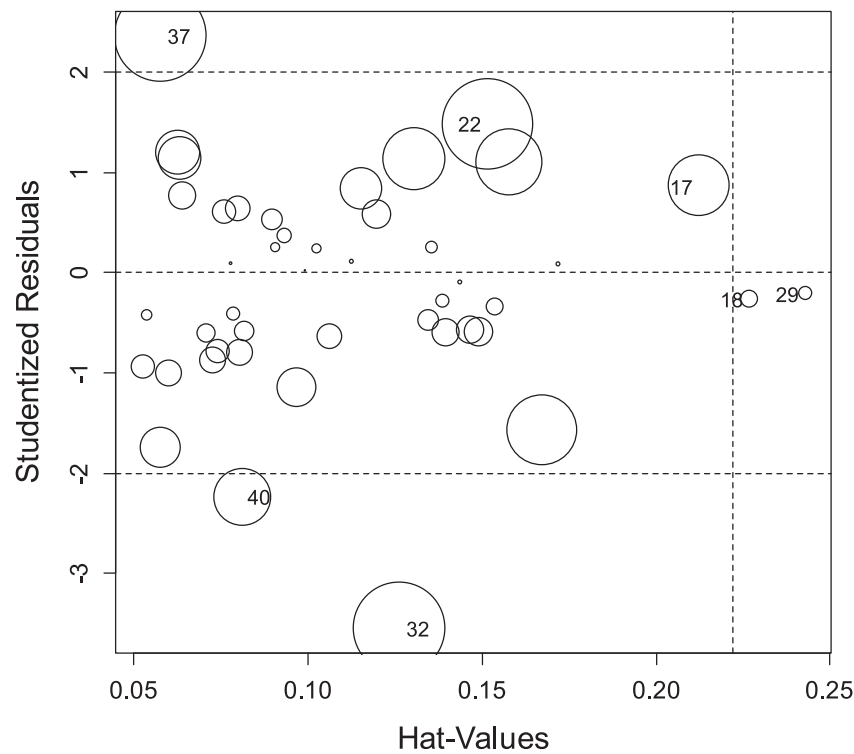

Fig. 6. Bubble plot of hat-values, studentized residuals, and Cook's distances of the observations after fit of the candidate negative binomial regression model: $\widehat{\log (P f)}=-\hat{\beta}_{0}+\hat{\beta}_{1} \log P i+\hat{\beta}_{2} p H+\hat{\beta}_{3}$ Tillage $-\hat{\beta}_{4} T I$. Size of the circle is proportional to Cook's Distance. Observations with large hat values are observations with high leverage. 


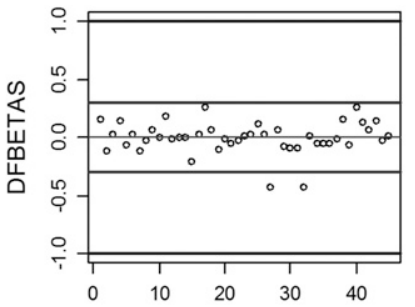

Observation number

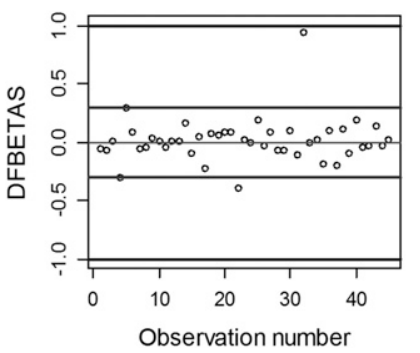

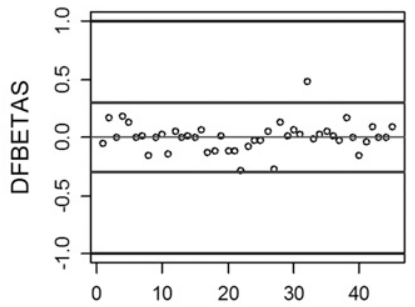

Observation number

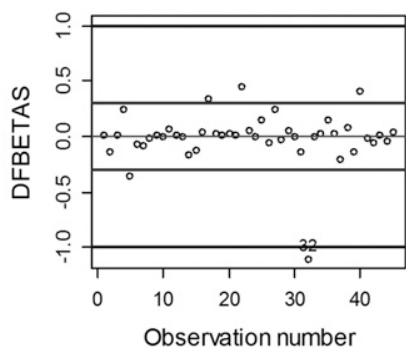

Fig. 7. DFBETAS values of the observations after fit of the candidate negative binomial regression model: $\widehat{\log (P f)}=-\hat{\beta}_{0}+\hat{\beta}_{1} \log P i+\hat{\beta}_{2} p H+\hat{\beta}_{3}$ Tillage $-\hat{\beta}_{4} T I$, where A, SCN initial population density, $\mathbf{B}$, Soil pH, C, Tillage, and D, Texture index. Influential observations on the estimated coefficients are shown outside the border lines with absolute value $>1$. final model were 510.82 and 516.93, respectively, whereas for the intercept-only model, these information criteria were 568.7 and 571.8. The Pearson $\chi^{2} / \mathrm{df}$ or dispersion statistics was 1.04 for the final model and 1.16 for intercept-only model.

Model validation. Little change in the regression coefficients and their associated significance level was observed in the model fitted to the 50 and $75 \%$ random samples from the data set (Table 6). In the $50 \%$ random sample, the relative change in the regression coefficients was $11.3 \%$ for the intercept, $1.2 \%$ for $\beta 1$, and $10.1 \%$ for $\beta 2$, whereas in the $75 \%$ sample the relative change was $3.7,1.6$, and $0.07 \%$, for the intercept, $\beta 1$, and $\beta 2$, respectively (Table 6 ). The sign and level of significance for the coefficients did not change in either sample. The $R^{2}$ value from the regression between the observed and estimated SCN final population density values in the $50 \%$ sample data set was 0.79 , and the slope of the regression line was not significantly different from $1(P=0.99$, Fig. 8$)$. Likewise, in the $75 \%$ sample data set, $R^{2}$ was 0.84 and the slope was not significantly different from 1 ( $P=0.97$, Fig. 9). The model showed a good performance in predicting single observations (Table 7).

\section{Discussion}

A modeling approach was used in this study in an attempt to identify major factors associated with the SCN population density reduction observed after annual corn rotation in Nebraska. A final regression model with SCN spring population density $(\mathrm{P} i)$ and soil $\mathrm{pH}$ as predictors was developed. The final model, based on the

Table 5. Estimates of the regression coefficients, significance level, and relative percent change in the coefficient estimates after fit of the candidate negative binomial regression model before and after removal of observations 32 and 37

\begin{tabular}{|c|c|c|c|c|c|c|c|c|c|c|}
\hline \multirow[b]{2}{*}{ Coefficient } & \multicolumn{3}{|c|}{ Whole data set } & \multicolumn{3}{|c|}{ Without observation 32} & \multicolumn{3}{|c|}{ Without observation 37} & \multirow{2}{*}{$\frac{\text { Without } 32 \text { and } 37}{\text { Relative change }(\%)}$} \\
\hline & Estimate & Std error & $P>\mathrm{Z}$ & Estimate & $P>Z$ & Relative change $(\%)$ & Estimate & $P>Z$ & Relative change (\%) & \\
\hline Intercept & -2.5384 & 0.6009 & $<0.0001$ & -2.4292 & $<0.0001$ & 4.3 & -2.6171 & $<0.0001$ & 3.1 & 1.2 \\
\hline $\log i^{v}$ & 0.8342 & 0.0511 & $<0.0001$ & 0.8492 & $<0.0001$ & -1.8 & 0.8325 & $<0.0001$ & 0.2 & -1.6 \\
\hline $\mathrm{pH}^{\mathrm{w}}$ & 0.4395 & 0.0690 & $<0.0001$ & 0.4136 & $<0.0001$ & 5.9 & 0.4446 & $<0.0001$ & 1.16 & 4.6 \\
\hline Tillage $^{x}$ & 0.3340 & 0.1488 & 0.0248 & -0.2688 & 0.0423 & 180.5 & -0.3796 & 0.0030 & 213.7 & 5.4 \\
\hline $\mathrm{TI}^{\mathrm{y}}$ & -0.0830 & 0.0550 & 0.1312 & -0.0578 & 0.2200 & 30.4 & -0.0680 & 0.2327 & 18.1 & 46.9 \\
\hline & & $1.02^{\mathrm{z}}$ & & & $1.15^{\mathrm{z}}$ & & & $0.98^{\mathrm{z}}$ & & $1.11^{\mathrm{z}}$ \\
\hline
\end{tabular}

v SCN initial population density natural-log transformed.

w Soil pH.

$x$ As a binary variable: till versus no till.

y Texture index calculated from a principal component analysis of sand, silt, and clay.

$\mathrm{z}$ Model dispersion statistics or Pearson $\chi^{2} / \mathrm{df}$.

Table 6. Relative change in the estimates of the regression coefficients of the final negative binomial regression model fitted to two random samples compared with fit to the entire data set

\begin{tabular}{|c|c|c|c|c|c|c|c|c|c|}
\hline \multirow[b]{2}{*}{ Coefficient } & \multicolumn{3}{|c|}{ Whole data set } & \multicolumn{3}{|c|}{$\mathbf{5 0 \%}$ random sample } & \multicolumn{3}{|c|}{$75 \%$ random sample } \\
\hline & Estimate & Std error & $P>Z$ & Estimate & $P>\mathrm{Z}$ & Relative change (\%) & Estimate & $P>\mathrm{Z}$ & Relative change (\%) \\
\hline Intercept & -2.3360 & 0.6009 & $<0.0001$ & -2.0731 & 0.0035 & 11.3 & -2.2457 & 0.0038 & 3.9 \\
\hline $\log i^{\mathrm{x}}$ & 0.8368 & 0.0511 & $<0.0001$ & 0.8266 & $<0.0001$ & 1.2 & 0.8234 & $<0.0001$ & 1.6 \\
\hline $\mathrm{pH}^{\mathrm{y}}$ & 0.4333 & 0.0690 & $<0.0001$ & 0.3870 & $<0.0001$ & 10.1 & 0.4336 & $<0.0001$ & 0.07 \\
\hline & $1.04^{\mathrm{z}}$ & & & $1.01^{\mathrm{z}}$ & & & $0.95^{\mathrm{z}}$ & & \\
\hline
\end{tabular}

x SCN initial population density (eggs $100 \mathrm{~cm}^{-3}$ of soil, natural log-transformed).

y Soil pH.

${ }^{\mathrm{z}}$ Model dispersion statistics or scaled Pearson $\chi^{2} / \mathrm{df}$.

Table 7. Analysis of fixed effects (intercept and explanatory variables) from fitting of the final negative binomial regression model using robust estimation of standard errors

\begin{tabular}{lcccrr}
\hline Effect & Estimate & Std error & $\mathbf{9 5 \%}$ Confidence limits & $\boldsymbol{Z}$ value & \multicolumn{1}{c}{$\boldsymbol{P} \mathbf{Z}$} \\
\hline Intercept & -2.3360 & 0.7171 & $-3.7414-0.9306$ & -4.40 \\
$\mathrm{Pi}^{\mathrm{x}}$ & 0.8368 & 0.0627 & 0.71380 .9597 & 18.49 \\
$\mathrm{pH}^{\mathrm{y}}$ & 0.4333 & 0.0849 & 0.26700 .5997 & 8.01 & $<0.0001$ \\
& $1.04^{\mathrm{z}}$ & & & & $<0.0001$ \\
\end{tabular}

${ }^{x}$ SCN initial population density (eggs $100 / \mathrm{cm}^{3}$ of soil, natural log-transformed).

y Soil pH.

${ }^{\mathrm{z}}$ Model dispersion statistics or Pearson $\chi^{2} / \mathrm{df}$. 
negative binomial distribution, was developed through a careful cycle of model specification, estimation, testing, and validation. The type of parameterization of the negative binomial used in this study, referred to as traditional negative binomial model or NB2, is the most common implementation of the negative binomial (Cameron and Trivedi 2013). In this type of parameterization, the conditional variance is modeled as a quadratic function of the mean: $\mu+\alpha \mu^{2}$ and model parameters are estimated with standard maximum likelihood (Hilbe 2014). Equidispersion, a condition assumed by the standard Poisson distribution, stipulates equality of the conditional mean and variance and is a crucial requirement in count data models for efficient estimators and valid inference (Hilbe 2014). In the present study, a rigorous assessment of overdispersion was made during the model development process. The overdispersion statistics in the final model developed in the study indicated $4 \%$ of unexplained correlation in the data. Given the relatively small data set on which the model was built and the parsimony of the model itself, this unexplained correlation was regarded as acceptable in selection of the final model.

On model construction. Given the size of the data set on which the model was built, little emphasis was placed on fitting models with main effects, quadratic forms, and interactions. Instead, focus was on fitting a few models with explanatory variables for which an association with the observed population density after annual corn rotation (Pf) was consistently suggested by the diagnostics, goodness-of-fit tests, and remedial measures. Since $\mathrm{P} f$ is a count type response variable and because its unconditional distribution was highly skewed, a Poisson model appeared to be the first natural model choice to pursue. However, true overdispersion was confirmed, thus suggesting use of an alternative model to Poisson.

Model interpretation. The final model $\mathrm{P} f=\exp ^{\{-2.3360+0.8368(\log \mathrm{P} i)}$ $+0.4333 \mathrm{pH}\}$ developed in this study suggested that the SCN population density reduction after annual corn rotation depended greatly on the SCN Pi and soil pH. In the context of the population of inference for this study and applying the model equation to different scenarios of $\mathrm{P} i$ and $\mathrm{pH}$, the model indicates that within the $\mathrm{SCN}$ initial population density range 363 to $16,954 \mathrm{eggs} / 100 \mathrm{~cm}^{3}$ of soil, a

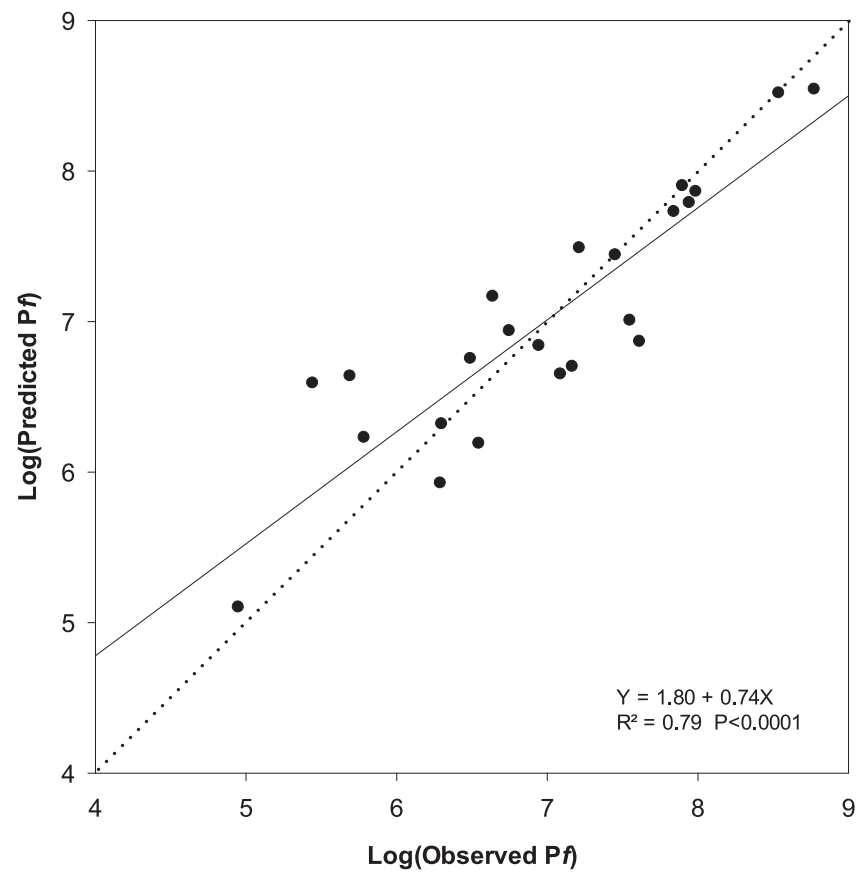

Fig. 8. Relationship between the log of the observed SCN population density after annual corn rotation in Nebraska (Pf) and the log of the SCN Pf predicted with the final negative binomial regression model built on a $50 \%$ random sample. Model included SCN initial population density and soil pH as predictors. Solid line is the regression line and dotted line is the line with slope 1 passing through the origin. The regression equation and the $R^{2}$, rounded to nearest two decimals, are shown in the graphic.
$10 \%$ change in $\mathrm{P} i$ will result in an $8.3 \%$ change in $\mathrm{P} f$, holding $\mathrm{pH}$ constant. Likewise, within the $\mathrm{pH}$ range 5.5 to 8.1 , for every unit increase in soil $\mathrm{pH}, \mathrm{SCN} \mathrm{P} f$ is expected to increase by $53.7 \%$ holding $\mathrm{P} i$ constant. In terms of SCN population density reduction, the general interpretation of the model is that in fields with high $\mathrm{pH}$ soils, the annual SCN population density reduction is expected to be lower at constant Pi. Likewise, the higher the SCN spring population densities (before rotation), the lower the SCN population density reduction at constant soil $\mathrm{pH}$. The $\mathrm{pH}$ range values on which this model was built (5.5 to 8.1) is representative of the soil $\mathrm{pH}$ values found in Nebraska fields where soybean is grown. Our model establishes a quantitative relationship of field SCN mortality with $\mathrm{pH}$ for the first time. The range values of the response variable varied from 590 to about $16,000 \mathrm{eggs} / 100 \mathrm{~cm}^{3}$ of soil, which encompasses what in the literature is considered as low and high ranges of SCN population densities.

Relationship between variables. The relationship between soil $\mathrm{pH}$ and the SCN final population densities revealed from our model is in agreement with the association between soil $\mathrm{pH}$ and SCN reported in other studies (Francl 1993; Pedersen et al. 2010; Rogovska et al. 2009). The general observation is that higher SCN population densities occur in higher $\mathrm{pH}$ soils. The specific mechanisms by which soil $\mathrm{pH}$ affects SCN are not well understood, although it is reported that $\mathrm{pH}$ can affect hatching and survival of nematode species other than SCN (Rogovska et al. 2009). We speculate that high pH could prevent SCN cyst hatching during annual corn rotation, that is, in the absence of soybean root stimulus.

While in this data set only SCN $\mathrm{P} i$ and $\mathrm{pH}$ showed the strongest explanatory power of the SCN population density reduction after annual corn rotation, the extra $4 \%$ correlation (Pearson dispersion statistics $=1.04)$ not explained by the model suggests that other variables and interactions could contribute to the observed SCN population density decline. In our analysis, other variables suggested as potential predictors of SCN Pf were tillage, texture index, and soil temperature. These variables were relatively near the marginal level of significance in the model construction process both in the firstorder and the candidate model, and they have been associated to

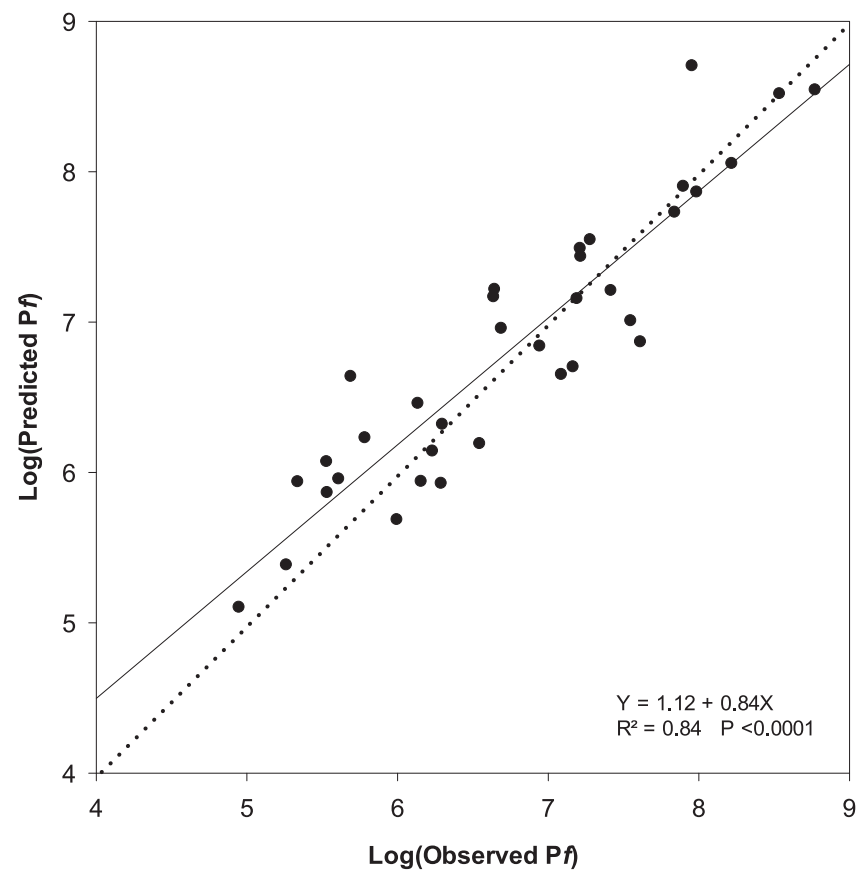

Fig. 9. Regression of the log of the observed SCN population density after annual corn rotation in Nebraska (Pf) versus the log of the SCN Pf predicted with the final negative binomial regression model in a $75 \%$ random sample from the original data set. Model included SCN initial population density and soil pH as predictors. Solid line is the regression line and dotted line is the line with slope 1 passing through the origin. The regression equation and the $R^{2}$, rounded to nearest two decimals, are shown in the graphic. 
SCN population densities (Workneh et al. 1999). Previous studies on the relationship of soil texture with $\mathrm{SCN}$ indicate that higher SCN population densities are more commonly found in sandy than in fine-textured soils (Pérez-Hernández and Giesler 2014). However, how texture affects SCN mortality remains unclear. In the present study, it is suggested that in the latitudinal range where this study was carried out, texture may be a weak driving factor of the SCN population fluctuations in a normal year (Pérez-Hernández and Giesler 2014). With respect to tillage, previous research suggests that in notill fields, SCN population aggregation is increased, whereas in till fields aggregation remains low due to $\mathrm{SCN}$ dissemination, especially in the direction of tillage (Workneh et al. 1999). If future enhancements are to be done on the model developed in this study, soil texture, tillage, and soil temperature are suggested as explanatory variables to consider with a larger data set than the one used in this study.

In summary, the model developed in this study suggests that SCN spring population densities and soil $\mathrm{pH}$ are major determinants of the observed SCN population density reduction after annual corn rotation in Nebraska. This piece of information can be helpful in making decisions regarding SCN management, for example, in deciding on the number of cycles to keep a field under corn cultivation to further abate SCN population densities. The model has potential for use in SCN risk analysis and in predicting SCN population density decline after corn rotation in the state.

\section{Acknowledgments}

The authors thank Dr. Stephen Kachman for critical review and Robert J. Prochaska for his assistance in collecting the data for the project.

\section{Literature Cited}

Alston, D. G., and Schmitt, D. P. 1988. Development of Heterodera glycines life stages as influenced by temperature. J. Nematol. 20:366-372.

Cameron, A. C., and Trivedi, P. K. 2013. Regression Analysis of Count Data, 2nd ed. Cambridge University Press, New York.

Chen, S., Johnson, G. A., Warnke, S. A., Wyse, D. L., and Porter, P. M. 2008. Effect of rotation crops on hatch, viability and development of Heterodera glycines. Nematology 10:869-882.

Doupnik, B., Jr. 1993. Soybean production and disease loss estimates for North Central United States from 1989 to 1991. Plant Dis. 77:1170-1171.

Fox, J., and Weisberg, S. 2011. An R Companion to Applied Regression, 2nd ed. SAGE publications, Inc., Thousand Oaks.

Francl, L. J. 1993. Multivariate analysis of selected edaphic factors and their relationship to Heterodera glycines population density. J. Nematol. 25: $270-276$.

Giesler, L. J., and Wilson, J. A. 2011. Soybean cyst nematode: Identification and management. Ext. Publ. \# G32. University of Nebraska-Lincoln, Lincoln, NE.

Hilbe, J. M. 2011. Negative Binomial Regression, 2nd ed. Cambridge University Press, New York.

Hilbe, J. M. 2014. Modeling Count Data. Cambridge University Press, New York.

Hubbard, K. G., and You, J. 2005. Sensitivity analysis of quality assurance using the spatial regression approach $-\mathrm{A}$ case study of the maximum/minimum air temperature. J. Atmos. Ocean. Technol. 22:1520-1530.

Johnson, W. G., Creech, J. E., and Mock, V. A. 2008. Role of winter annual weeds as alternative hosts for soybean cyst nematode. Online. Crop Manag. 7:1.

Jones, F. G. W., and Perry, J. N. 1978. Modelling populations of cyst-nematodes (Nematoda: Heteroderidade). J. Appl. Ecol. 15:349-371.

Khan, M. R. 2008. Plant Nematodes: Methodology, Morphology, Systematics, Biology and Ecology. Science Publishers, Enfield.
Koenning, S. R., Schmitt, D. P., and Barker, K. R. 1993. Effects of cropping systems on population density of Heterodera glycines and soybean yield. Plant Dis. 77:780-786.

Kutner, M. H., Nachtsheim, C. J., and Neter, J. 2004. Applied Linear Regression Models. McGraw-Hill, New York.

Lauritis, J. A., Rebois, R. V., and Graney, I. S. 1983. Development of Heterodera glycines Ichinohe on soybean Glycine $\max (\mathrm{L}$.) Merr., under gnotobiotic conditions. J. Nematol. 15:272-281.

National Agricultural Statistics Service. 2018. United States Department of Agriculture. Nebraska Agriculture Overview. https://www.nass.usda.gov/Quick Stats/Ag_Overview/stateOverview.php?state=NEBRASKA.

Niblack, T. L. 2005. Soybean cyst nematode management reconsidered. Plant Dis. 89:1020-1026.

Noel, G. R. 2008. IPM of soybean cyst nematode in the US. Pages 119-126 in: Integrated Management and Biocontrol of Vegetable and Grain Crops Nematodes. A. Ciancio and K. G. Mukerji, eds. Springer, The Netherlands.

Paul, P. A., and Munkvold, G. P. 2005. Regression and artificial neural network modeling for the prediction of gray leaf spot of maize. Phytopathology 95: 388-396.

Pedersen, P., Tylka, G. L., Mallarino, A., Macguidwin, A. E., Koval, N. C., and Grau, C. R. 2010. Correlation between soil pH, Heterodera glycines population densities, and soybean yield. Crop Sci. 50:1458-1464.

Pérez-Hernández, O., and Giesler, L. J. 2014. Quantitative relationship of soil texture with soybean cyst nematode (Heterodera glycines Ichinohe) populations in soybean and in soybean fields annually rotated to corn in Nebraska. J. Nematol. 46:90-100.

Porter, P. M., Chen, S. Y., Reese, C. D., and Klossner, L. D. 2001. Population response of soybean cyst nematode to long term corn-soybean cropping sequences in Minnesota. Agron. J. 93:619-626.

Riggs, R. D. 1992. Host range. Pages 107-114 in: Biology and Management of the Soybean Cyst Nematode. R. D. Riggs and J. A. Wrather, eds. American Phytopathological Society, St. Paul, MN.

Rogovska, N. P., Blackmer, A. M., and Tylka, G. L. 2009. Soybean yield and soybean cyst nematode densities related to soil $\mathrm{pH}$, soil carbonate concentrations, and alkalinity stress index. Agron. J. 101:1019-1026.

Ross, J. P. 1962. Crop rotation effects on the soybean cyst nematode population and soybean yields. Phytopathology 52:815-818.

Ross, J. P. 1964. Effect of soil temperature on development of Heterodera glycines in soybean roots. Phytopathology 54:1228-1231.

Sinnott, R. W. 1984. Virtues of the Haversine. Sky Telescope 68:159.

Slack, D. A., Riggs, R. D., and Hamblen, M. L. 1972. The effect of temperature and moisture on the survival of Heterodera glycines in the absence of a host. J. Nematol. 4:263-266.

Stroup, W. W. 2013. Generalized Linear Mixed Models: Modern Concepts, Methods and Applications. CRC Press, Boca Raton, FL.

Svetliza, C. F., and Paula, G. A. 2003. Diagnostics in nonlinear negative binomial models. Commun. Stat. Theory Methods 32:1227-1250.

Westphal, A., Xing, L. J., Pillsbury, R., and Vyn, T. J. 2009. Effect of tillage intensity on population densities of Heterodera glycines in intensive soybean production systems. Field Crops Res. 113:218-226.

Wilson, J., and Giesler, L. J. 2013. Tode awards recognize results of SCN sampling. University of Nebraska-Lincoln. https://cropwatch.unl.edu/tode-awards-recognizeresults-scn-sampling

Winstead, N. N., Skotland, C. B., and Sasser, J. N. 1955. Soybean cyst nematode in North Carolina. Plant Dis. Rep. 39:9-11.

Workneh, F., Yang, X. B., and Tylka, G. L. 1999. Soybean brown stem rot, Phytophthora sojae, and Heterodera glycines affected by soil texture and tillage relationships. Phytopathology 89:844-850.

Wrather, J. A. 2008. Impact of SCN on world soybean supply. Pages 1-3 in: Proceedings of the 4th National Soybean Cyst Nematode Conference. Tampa, FL.

Wrather, J. A., and Koenning, S. R. 2006. Estimates of disease effects on soybean yields in the United States 2003 to 2005. J. Nematol. 38:173-180.

Young, L. D., and Hartwig, E. E. 1992. Cropping sequence effects on soybean and Heterodera glycines. Plant Dis. 76:78-81. 